\title{
Araştırma Makalesi https://doi.org/10.33484/sinopfbd.651335 Log-Lineer Modeller ve Kadına Yönelik Şiddet Üzerine Bir Uygulama
}

\author{
Tuğba ÇAĞILCI, Nazan DANACIOĞLU* \\ Sinop Üniversitesi İstatistik Bölümü, SINNOP
}

$\ddot{\mathbf{O z}}$

Kategorik değişkenler sosyal ve davranışsal bilimlerde yaygın olmasına rağmen, kullanımları sadece bu alanlarla sınırlı değildir. Bu tür değişkenler genellikle çapraz tablolar şeklinde düzenlenmektedir. 2-boyutlu çapraz tablolar, iki kategorik değişkenin bağımsız olup olmadığına odaklanmaktadır. İkiden fazla kategorik değişkenin olduğu durumlarda, iki ya da daha fazla kategorik değişken arasındaki ilişki yapısını inceleyen log-lineer modeller kullanılabilir. Log-lineer modellerde, tam bağımsızlık modeli, kısmi bağımsızlık modeli, koşullu bağımsızlık modeli, homojen ilişki modeli ve doymuş model gibi çeşitli modellerin tahmin edilmesi ile en uygun model belirlenmektedir. Temel amaç, değişkenler arasındaki bazı bağımsızlık tiplerini ve değişkenler arasındaki ilişkiyi belirlemektir. Bu çalışmada, loglineer modeller üç-boyutlu çapraz tabloların analizinde kullanılmış, uygun modelin seçilmesi aşaması incelenmiştir. Bu amaçla, uygulamada, TÜİK (Türkiye İstatistik Kurumu) tarafından yapılan "Türkiye'de Kadına Yönelik Aile İçi Şiddet Araştırması" (2008) mikro verisi kullanılarak üç-boyutlu bir çapraz tablo oluşturulmuştur.

Anahtar Kelimeler: Log lineer modeller, çapraz tablolar, kadına şiddet

\section{An Application on Log-Linear Models and Violence Against Women}

\begin{abstract}
Although categorical variables are common in the social and behavioral sciences, their usage are not restricted to those areas. These kind of variables are generally represented by contingency tables. Two-way contingency tables emphasize whether the two categorical variables are independent. If there are more than two categorical variables, log-linear models can be used for the relationship among two or more categorical variables. In the log-linear models, the most appropriate model is determined by the fit of the various models, such as full independence, partial independence, conditional independence, homogeneous relationship and saturated models. The main purpose is to determine some types of independence between variables and the relationship among the variables. In this study, log-linear models are used to analyze three-way contingency tables, and selection of the appropriate model is examined. For this purpose, TSI (Turkish Statistical Institute) "The Research on Domestic Violence against Women in Turkey" 2008 raw data set is used to construct a three-way contingency table.
\end{abstract}

Keywords: Log-linear models, contingency tables, violence against women

\footnotetext{
${ }^{*}$ Sorumlu Yazar: ORCID ID: orcid.org/0000-0001-8014-6920

e-mail: nazand@sinop.edu.tr
}

Received: 26.11 .2019

Accepted: 22.01 .2020 


\section{Giriș}

Sosyal bilimlerle ilgili yapılan araştırmalarda genellikle değişkenlerin ölçüm düzeyi sınıflama (nominal) ve sıralama (ordinal) türü ölçekle ölçüldüğünde, parametrik olmayan teknikler uygun olmaktadır. Bilindiği gibi, çapraz sınıflandırılmış kategorik verilerin iki-boyutlu olması durumunda Pearson $\chi^{2}$ istatistiği ve $G^{2}$ olabilirlik oran testi kullanılmaktadır.

Üç-boyutlu çapraz sınıflanmış verilerin analizi söz konusu olduğunda, mümkün olan 2-değişkenli marjinal tabloların elde edilerek ayrı ayrı klasik $\chi^{2}$ testi uygulanması, yüksek dereceden etkileşimin ihmal edilmesine ve incelemeye alınmayan üçüncü değişkenin, diğer değişkenler üzerindeki etkisi ayırt edilemediğinden bilgi kaybına neden olmaktadır.

Verilerin 2-3 veya çok-boyutlu çapraz tablolarla ifade edildiği durumlarda, log-lineer modeller, çapraz tablolardaki göze sıklıklarını modellemek için kullanılır ve kategorik değişkenler kümesi arasındaki ilişki yapılarını tanımlar.

Log-lineer analizde verinin toplanma biçimine göre bir dağılım varsayımı yapılır; modelin doğru olduğu varsayımı altında tahminler elde edilir ve modelin veriye uygunluğunu test etmek için hipotez kurulur. Son olarak, modeli değerlendirmek için, bu tahminler gözlenen değerler ile karşılaştırılır. $\mathrm{Bu}$ yolla örneklem verisinden yararlanarak kitle hakkında çıkarsamalar yapılır [1].

Log-lineer analiz ile ilgili çalışmalar ülkemizde genellikle üç-boyutlu çapraz tablolar kullanılarak yapılmıştır. Bu çalışmalardan bazıları; [2], karayolları donanım durumunun trafik kazalarına etkisini araştırmış; [3], göç istatistikleri üzerine bir uygulama yapmış; [4], sigara bağımlılığını açıklayabilmek için log-lineer analizden yararlanmış; [5], trafik kaza verilerini log-lineer analiz ile incelemiş; [6], log-lineer modeller ve uyum analizini birlikte kullanarak, lise öğrencilerinin sigara içme alışkanlıklarını etkileyen faktörleri belirlemişlerdir.

Bu çalışmada da üç-boyutlu çapraz tablolar için log-lineer modellerin oluşturulması ve en uygun modelin seçilmesinin bir uygulama üzerinden açıklanması hedeflenmektedir.

\section{Üç-Boyutlu Çapraz Tablolar İçin Log- lineer Modeller}

Üç veya daha çok kategorik değişkenin bulunduğu çapraz tabloların çözümlemesinde, tüm değişkenlerin etkileşimlerinin modele alındığı hiyerarşik logaritmik doğrusal modeller kullanılmalıdır. Hiyerarşik logaritmik 
modeller, ana etkileri ve sırasıyla ikili, üçlü ve çoklu etkileşimleri modele alarak, en iyi modele ulaşan ve bulunan modele göre verileri analiz eden bir yöntemdir [7].

Üç boyutlu tablolarda i satır değişkenini, $\mathrm{j}$ sütun değişkenini ve $\mathrm{k}$ tabaka değișkenini göstermek üzere; A, B ve C kategorik değişkenlerinden oluşan üç boyutlu çapraz tablo için doymuş (saturated) log-lineer model aşağıdaki gibi yazılabilir:

$\log \left(\mathrm{f}_{i j k}\right)=\lambda+\lambda_{i}^{A}+\lambda_{j}^{B}+\lambda_{k}^{C}+\lambda_{i j}^{A B}+\lambda_{i k}^{A C}+\lambda_{j k}^{B C}+\lambda_{i j k}^{A B C}$

Burada,

$\lambda_{i}^{A}, \quad \lambda_{j}^{B}, \quad \lambda_{k}^{C}$, sirasiyla $\mathrm{A}, \mathrm{B}$ ve $\mathrm{C}$ değişkenlerinin ana etkilerini,

$\lambda_{i j}^{A B}, A$ ve $\mathrm{B}$ değişkenlerinin birlikte etkileşimini,

$\lambda_{i k}^{A C}, A$ ve $\mathrm{C}$ değişkenlerinin birlikte etkileşimini,

$\lambda_{j k}^{B C}$, B ve $\mathrm{C}$ değişkenlerinin birlikte etkileşimini,

$\lambda_{i j k}^{A B C}$, Tüm değişkenlerin birlikte etkileşimini göstermektedir [8].

Üç boyutlu çapraz tablolar için Eşitlik (1)'de verilen log-lineer modelin parametreleri, $\lambda=f$

$\lambda_{i}^{A}=f_{\mathrm{i..}}-f_{\ldots}$

$\lambda_{j}^{B}=f_{. \mathrm{j} .}-f_{\ldots}$

$\lambda_{k}^{c}=f_{. . k}-f_{. .}$

$\lambda_{i j}^{A B}=f_{\mathrm{ij} .}-f_{\mathrm{i} . .}-f_{. j .}+f_{\ldots}$

$\lambda_{i k}^{A C}=f_{i . k}-f_{i . .}-f_{. . \mathrm{k}}+f_{. .}$

$\lambda_{j k}^{B C}=f_{. j k}-f_{. j .}-f_{. . k}+f_{. .}$

$\lambda_{i j k}^{A B C}=f_{\mathrm{ijk}}-f_{\mathrm{ij} .}-f_{\mathrm{i} . \mathrm{k}}-f_{. \mathrm{jk}}+f_{\mathrm{i} . . .}+f_{\mathrm{j} .}+f_{. . \mathrm{k}}+f_{\ldots .}$

biçiminde yazılabilir [9].

$\mathrm{Bu}$ parametrelerde bulunan terimler aşağıdaki gibi hesaplanmaktadır:

$f_{i j k}=\operatorname{lnm}_{i j k} ; \quad f_{\ldots}=\frac{\sum_{i=1}^{I} \sum_{j=1}^{J} \sum_{k=1}^{K} f_{i j k}}{I J K} ;$

$f_{i . .}=\frac{\sum_{j=1}^{J} \sum_{k=1}^{K} f_{i j k}}{J K} ; \quad f_{. j .}=\frac{\sum_{i=1}^{I} \sum_{k=1}^{K} f_{i j k}}{I K}$;

$f_{. . k}=\frac{\sum_{i=1}^{I} \sum_{j=1}^{J} f_{i j k}}{I J} \quad f_{i j .}=\frac{\sum_{k=1}^{K} f_{i j k}}{K}$;

$f_{i . k}=\frac{\sum_{j=1}^{J} f_{i j k}}{J} ; \quad f_{. j k}=\frac{\sum_{i=1}^{I} f_{i j k}}{I}$

A, B ve C kategorik değişkenlerine sahip üç boyutlu IxJxK çapraz tablosu, bağımsızlığın farklı tiplerine sahiptir. 


\section{Modellerin Açıklanması}

Üç-boyutlu çapraz tablolarda, ilgilenilen 8 model vardır. $\mathrm{Bu}$ tür tablolarda üç boyut; satır, sütun ve tabaka olarak adlandırıldığında, ilk model $\left(\mathrm{M}_{0}\right)$ tam bağımsızlık modeli olup, bu modelde, satır, sütun ve tabaka değişkenleri birbirinden bağımsızdır:

$$
\begin{aligned}
& \log _{i j k}=\lambda+\lambda_{i}^{A}+\lambda_{j}^{B}+\lambda_{k}^{C} \\
& i=1,2, \ldots, I, j=1,2, \ldots, J, k=1,2, \ldots, \mathrm{K}
\end{aligned}
$$

Kısmi bağımsızlık modelleri olarak adlandırılan 3 model; satır, sütun ve tabakadan bağımsızdır $\left(\mathrm{M}_{1}\right)$; sütun, satır ve tabakadan bağımsızdır $\left(\mathrm{M}_{2}\right)$ ve tabaka, satır ve sütundan bağımsızdır $\left(\mathrm{M}_{3}\right)$ olarak tanımlanır. $M_{1}$ modelinin gösterimi Eşitlik (3)'teki gibidir:

$$
\begin{aligned}
& \log _{i j k}=\lambda+\lambda_{i}^{A}+\lambda_{j}^{B}+\lambda_{k}^{C}+\lambda_{i k}^{A C} \\
& i=1,2, \ldots, I, j=1,2, \ldots, J, k=1,2, \ldots, \mathrm{K}
\end{aligned}
$$

Koşullu bağımsızlık modelleri de 3 tane olup; bu modellerde bir değişkenin sabit olduğu her kısmi tablo için, diğer değişkenler koşullu bağımsız olarak tanımlanmaktadır [8]. $\mathrm{Bu}$ modeller; herhangi bir tabakanın düzeylerinde satır ve sütun bağımsızdır $\left(\mathrm{M}_{4}\right)$; herhangi bir sütunun düzeylerinde, satır ve tabaka bağımsızdır $\left(\mathrm{M}_{5}\right)$; herhangi bir satır verildiğinde, sütun ve tabaka bağımsızdır
(M). M5 modeli Eşitlik (4)’te gösterildiği gibidir:

$$
\begin{aligned}
& \log _{i j k}=\lambda+\lambda_{i}^{A}+\lambda_{j}^{B}+\lambda_{k}^{C}+\lambda_{i k}^{A C}+\lambda_{j k}^{B C} \\
& \quad i=1,2, \ldots, I, j=1,2, \ldots, J, k=1,2, \ldots, \mathrm{K}
\end{aligned}
$$

M8 modeli Eşitlik (5)'te verilen homojen ilişkili (homogeneous association) modelidir ve bütün değişken çiftlerinin koşullu bağımsızlığını gösterir. $\mathrm{Bu}$ model için; herhangi iki değişken

\begin{tabular}{|c|c|c|c|c|}
\hline Model & \multicolumn{2}{|c|}{ Gösterim } & $\mathrm{H}_{0}$ & $\begin{array}{c}\text { SD } \\
\text { (Serbestlik }\end{array}$ \\
\hline Tam Bağımsizllk & $(\mathrm{A}, \mathrm{B}, \mathrm{C})$ & $\mathrm{M}_{0}$ & $\lambda_{i j k}=\lambda_{i, \ldots} \lambda_{j} \lambda_{k}$ & RCK-R-C-K+2 \\
\hline \multirow{3}{*}{ Kısmı Bağmsızllk } & $(\mathrm{A}, \mathrm{BC})$ & $\mathrm{M}_{1}$ & $\lambda_{j \mid k}=\lambda_{4 . . j} \lambda_{j k}$ & $(\mathrm{R}-1)(\mathrm{CK}-1)$ \\
\hline & $(\mathrm{B}, \mathrm{AC})$ & $\mathrm{M}_{2}$ & $\lambda_{j i k}=\lambda_{j} \lambda_{i k}$ & (C-1)(RK-1) \\
\hline & $(\mathrm{C}, \mathrm{AB})$ & $\mathrm{M}_{3}$ & $\lambda_{j i j k}=\lambda_{, k} \lambda_{j .}$ & $(\mathrm{K}-1)(\mathrm{RC}-1)$ \\
\hline \multirow{3}{*}{$\begin{array}{l}\text { Koşulllı } \\
\text { Bağmsinsllkk }\end{array}$} & $(\mathrm{AC}, \mathrm{BC})$ & $\mathrm{M}_{4}$ & $\lambda_{i k}=\lambda_{i k} \lambda_{j, k} / \lambda_{-k}$ & $\mathrm{~K}(\mathrm{R}-1)(\mathrm{C}-1)$ \\
\hline & $(\mathrm{AB}, \mathrm{BC})$ & $\mathrm{M}_{5}$ & $\lambda_{i j k}=\lambda_{i j} \lambda_{j k} / \lambda_{i j}$ & $C(\mathrm{R}-1)(\mathrm{K}-1)$ \\
\hline & $(\mathrm{AC}, \mathrm{AB})$ & $\mathrm{M}_{6}$ & $\lambda_{\text {IR }}=\lambda_{i_{1}} \lambda_{j, k} / \lambda_{\text {. }}$ & $\mathrm{R}(\mathrm{C}-1)(\mathrm{K}-1)$ \\
\hline $\begin{array}{l}\text { Homojen Iliskili } \\
\text { Model }\end{array}$ & $(\mathrm{AB}, \mathrm{AC}, \mathrm{BC})$ & $\mathrm{M}_{7}$ & $\lambda_{i k}=\lambda_{i j} \lambda_{i k} \lambda_{j, k}$ & $(\mathrm{R}-1)(\mathrm{C}-1)(\mathrm{K}-1)$ \\
\hline
\end{tabular}
arasındaki koşullu odds oranları, üçüncü değişkenin her bir düzeyinde aynıdır [8].

$$
\begin{array}{rlrl}
\operatorname{logf}_{i j k}= & \lambda+\lambda_{i}^{A}+\lambda_{j}^{B}+\lambda_{k}^{C}+\lambda_{i j}^{A B}+\lambda_{i k}^{A C}+\lambda_{j k}^{B C} & (5) \\
& i=1,2, \ldots, l, & j=1,2, \ldots, J, \\
& k=1,2, \ldots, \mathrm{K} & & \text { Üç-boyutlu } \\
& \text { çapraz tablolar } \quad \text { için } & \text { log-lineer } \\
& \text { modeller } & \text { Tablo } & 1 \text { 'de } \\
& \text { özetlenmektedir [15]. }
\end{array}
$$

Tablo 1. Log-lineer Modeller: $M_{0}, M_{1} \ldots M_{7}$ Modellerine Ait Genel Bilgiler 


\section{Modellerin Testi}

Üç-boyutlu tablolar için modellerin uygunluğu test edilirken, $\mathrm{G}^{2}$ olabilirlik oran test istatistiği kullanılmaktadır:

$$
G^{2}=2 \sum^{i j k} f_{i j k}\left(\ln f_{i j k}-\ln \frac{f_{i .} f_{. j} f_{. . k}}{n}\right)
$$

Ki kare testi büyük örneklemler için $G^{2}$ 'ye yaklaştığından dolayı, iki test istatistiği de birçok tabloda benzer değerlere sahiptir. Fakat $G^{2}$ olabilirlik oran istatistiği tam bölünebilme özelliğine sahip olduğundan $\mathrm{Ki}$ kare test istatistiğine karşı üstünlük sağlamaktadır [10].

\section{Uygun Modelin Seçimi}

Çok-boyutlu çapraz tablolarda tablo boyutu arttıç̧a, mümkün uygun model sayısı da artmaktadır. Buradaki amaç; veriyi açıklayan ya da veri yapısına uyan, mümkün olduğunca az parametreden oluşan modeli belirlemektir.

Üç-boyutlu tablolarda uygun modelin seçimi yapılırken, kullanılabilecek yaklaşımlardan biri, adımsal (stepwise) yöntemlerdir. Bunlar, basit modellere terimlerin eklendiği "ileriye doğru seçim"; başlangıçtaki en geniş modelden terimlerin çıkarıldığı "geriye doğruyu seçim” ve başlangıçtaki modele terimlerin eklenebileceği veya çıkartılabileceği "bileşik yöntemler" olarak üç şekilde sınıflandırılmaktadır. Herhangi bir model seçim ölçütüyle birlikte kullanılmadıklarında uygun model seçimi için güvenilir olmayabilmektedirler.

Modelde kaçıncı dereceden etkilerin bulunduğunu test etmek için kullanılan, K-yönlü etkilerin anlamlılığının test edilmesi; en uygun modelden ziyade, uygun model adaylarını belirlemek için kullanılır.

\section{Uygun Modelin Seçiminde Kısmi ve Marjinal İlișkiler}

[11] doymuş modeldeki (Eş.1) (bütün etkilerin dahil olduğu model) her terimin modelde olup olmayacağının kontrolünü sağlamak için, kısmi ve marjinal ilişki testlerini önermiştir. $\mathrm{Bu}$ testler, başlangıç modelini belirlemek için kullanılmaktadır.

Marjinal ilişki testi, k değişkenden oluşan marjinal tabloda, k-değişkenli etkileşim etkisinin sıfır olup olmadığının testi olarak tanımlanmaktadır [12].

Örneğin, A, B ve C'nin marjinal ilişki testi; tabloyu A, B, C marjinli hale indirgeyerek yapılır. Oluşturulan marjinal tabloda;

\section{$\mathrm{ABC}=0$ 'ın testi;}

(ABC) modeline karşı, (AB, AC, $\mathrm{BC})$ 'nin test edilmesidir.

\section{AD'nin marjinal ilişki testi;}

(AD)'ye karşı, (A, D)'nin test edilmesidir. 
[11]'in $\mathrm{k}$ değişken arasındaki kısmi ilişki testi ise, $\mathrm{k}$ dereceli modelin $\mathrm{G}^{2}$, si ile, ilgilenilen k-dereceden etkileşimin dahil olmadığı modelin $\mathrm{G}^{2}$, si arasındaki farktır [12].

Örneğin, 4 boyutlu bir çapraz tabloda, ABC teriminin kısmi ilişkisinin test edilebilmesi için; (ABC, ABD, ACD, $\mathrm{BCD}$ ) modeli ile (ABD, ACD, BCD) modelinin $\mathrm{G}^{2}$ 'ler ve serbestlik dereceleri arasındaki fark, $\mathrm{ABC}$ teriminin kısmi ilişkisinin test edilmesini sağlamaktadır.

[11]'in testlerini kullanarak başlangıç modeli seçmek için birkaç yöntem vardır [13]:

a) Marjinal testlerden önemli bulunan tüm terimlerin modele dahil edilmesi,

b) Kısmi testlerden önemli bulunan tüm terimlerin modele dahil edilmesi,

c) Marjinal ya da k1smi testlerde önemli bulunan bütün terimlerin modele dahil edilmesi,

d) Hem marjinal hem de k1smi testlerde önemli bulunan terimlerin modele dahil edilmesi.

Yöntem (d) her zaman en küçük modeli verirken, (c) yöntemi her zaman en büyük modeli vermektedir. Ayrıca (d) yöntemi ileriye doğru seçimde başlangıç modeli belirlemek için kullanılırken, (c) yöntemi geriye doğru seçimde başlangıç modeli

belirlemek

için

kullanılabilmektedir. Dört yöntemden herhangi biri bileşik adımsal yöntem için başlangıç modeli belirlemede kullanilabilmektedir [13].

\section{Bilgi Ölçütleri}

$\mathrm{Bu}$ çalışmada, uygun modeller arasından en uygun modelin belirlenmesi amacıyla kullanılan bilgi ölçütlerinden AIC (Akaike bilgi ölçütü) ve BIC (Bayesci bilgi ölçütü)'ye yer verilecektir. Bilgi ölçütleri genel olarak, bir modeli diğer bir modele karşı test etmekte kullanılan $\mathrm{G}^{2}$ test istatistiğinin yetersiz olduğu saviyla geliștirilmiștir [14].

$A I C=A_{\mathrm{M}}=G^{2}(\mathrm{M})-[\mathrm{q}-2 \mathrm{r}]$

$B I C=G^{2}-k \log n$

Uygulamada, en küçük AIC/BIC değerine sahip modelin en uygun model olduğuna karar verilir.

\section{Uygulama}

Üç-boyutlu çapraz tablo analizinde, log-lineer modellerin belirlenmesi ve en uygun modelin seçilmesine yönelik bu çalışmada; TÜİK (Türkiye İstatistik Kurumu) tarafindan yapılan "Türkiye'de Kadına Yönelik Aile İçi Şiddet Araştırması" (2008) mikro verisi kullanılarak oluşturulan üç-boyutlu çapraz tablolardan biri ele alınmıştır. Sözü edilen 
araștırmada, 12795 kadın katılımcıya anket yapılmıştır ve Türkiye'de kadına yönelik şiddetin boyutları ve nedenleri araştırılmıştır.

Tablo 2'de verilen üç-boyutlu çapraz tabloda yer alan değişkenlere ait bilgi aşağıda verilmiştir. Burada, intihar değişkenine karşılık gelen soru "Hayatınıza son vermeyi hiç düşündünüz mü?” şeklindedir [15].

Satır değișkeni:

Yaşadığı yer/İkamet adresi (Y);

1: Kent 2: Kir

Sütun değişkeni: İntihar (I);

1: İntiharı düşünenler

2: İntiharı düşünmeyenler

Tabaka değişkeni: Yaş(A);

1: 15-22 2: 23-30 3: 31-38 4: 39-46 5: 47+

Tablo 2. Yaşadiğg Yer, Yaş ve Intihar

Çapraz Tablosu

\begin{tabular}{|c|c|c|c|}
\hline $\begin{array}{c}\text { Yaşa dığı Yer } \\
(\mathbf{Y})\end{array}$ & \multirow{2}{*}{ Yaş (A) } & \multicolumn{2}{|c|}{ İntihar (İ) } \\
\cline { 2 - 4 } & & Evet & Hayır \\
\hline \multirow{4}{*}{ Kent } & $\mathbf{1 5 - 2 2}$ & 411 & 1146 \\
\cline { 2 - 4 } & $\mathbf{2 3 - 3 0}$ & 584 & 1751 \\
\cline { 2 - 4 } & $\mathbf{3 1 - 3 8}$ & 470 & 1766 \\
\cline { 2 - 4 } & $\mathbf{3 9 - 4 6}$ & 303 & 1285 \\
\cline { 2 - 4 } & $\mathbf{4 7 +}$ & 321 & 1390 \\
\hline \multirow{5}{*}{ Kur } & $\mathbf{1 5 - 2 2}$ & 148 & 445 \\
\cline { 2 - 4 } & $\mathbf{2 3 - 3 0}$ & 167 & 536 \\
\cline { 2 - 4 } & $\mathbf{3 1 - 3 8}$ & 151 & 535 \\
\cline { 2 - 4 } & $\mathbf{3 9 - 4 6}$ & 121 & 492 \\
\cline { 2 - 4 } & $\mathbf{4 7 +}$ & 122 & 641 \\
\hline
\end{tabular}

Öncelikle değişkenlerin bileşik, marjinal ve koşullu olasılıkları bulunmuş ve Tablo 3'te verilmiștir.
Tablo 3. Yaşadiğı Yer, Yaş ve İntihar İçin Bileșik ve Marjinal Olasılıklar

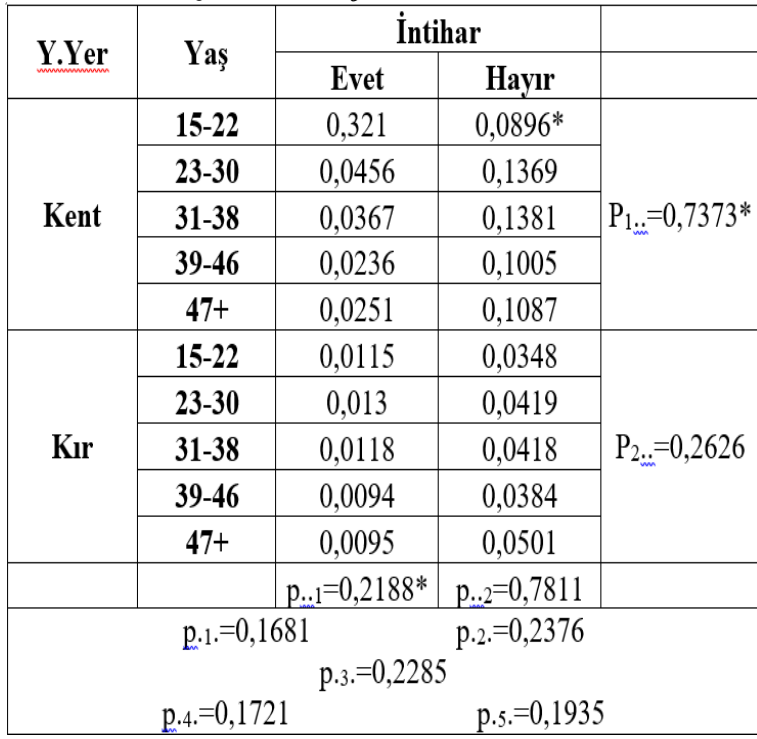

Tablo 3'ten de görüldügüü gibi, kentte yaşayan, yaşı 15-22 arasında olan ve intihar etmeyi düşünmeyen kadınların yüzdesi \%8,96'dır. Kadınların \%73,73’ü kentte yaşamaktadır. Ankete katılan kadınların \%21,88'i intihar etmeyi bir kez olsun düşündüklerini belirtmişlerdir.

Tablo 4'te çapraz tablo için koșullu olasılıklar görülmektedir. 
Tablo 4. Yaşadiğ Yer, Yaş ve İntihar İçin Koşullu Olasılıklar

\begin{tabular}{|c|c|c|c|}
\hline \multirow{2}{*}{ Yaşadığı yer } & \multirow{2}{*}{ Yaş } & \multicolumn{2}{|c|}{ İntihar } \\
\hline & & Evet & Hayir \\
\hline \multirow{15}{*}{ Kent } & \multirow{3}{*}{$15-22$} & $0,043^{*}$ & 0,1215 \\
\hline & & 0,1911 & 0,533 \\
\hline & & 0,1468 & 0,1147 \\
\hline & \multirow{3}{*}{ 23-30 } & 0,0619 & 0,1857 \\
\hline & & 0,1922 & 0,5763 \\
\hline & & 0,2087 & 0,1753 \\
\hline & \multirow{3}{*}{ 31-38 } & 0,049 & 0,1873 \\
\hline & & 0,1608 & $0,6043^{*}$ \\
\hline & & 0,1679 & 0,1768 \\
\hline & \multirow{3}{*}{$39-46$} & 0,032 & 0,1363 \\
\hline & & 0,1376 & 0,5838 \\
\hline & & 0,1082 & 0,1286 \\
\hline & \multirow{3}{*}{$47+$} & 0,034 & 0,1474 \\
\hline & & 0,1297 & 0,5618 \\
\hline & & 0,1147 & 0,1391 \\
\hline \multirow{15}{*}{ Kir } & \multirow{3}{*}{$15-22$} & 0,044 & 0,1325 \\
\hline & & 0,068 & 0,2069 \\
\hline & & 0,0528 & 0,044 \\
\hline & \multirow{3}{*}{ 23-30 } & 0,0497 & 0,1596 \\
\hline & & 0,0549 & 0,1764 \\
\hline & & 0,0596 & 0,0536 \\
\hline & \multirow{3}{*}{ 31-38 } & 0,0449 & 0,1593 \\
\hline & & 0,0516 & 0,183 \\
\hline & & 0,0539 & 0,0535 \\
\hline & \multirow{3}{*}{$39-46$} & 0,036 & 0,1465 \\
\hline & & 0,0549 & 0,2235 \\
\hline & & $0,0432 *$ & 0,0492 \\
\hline & \multirow{3}{*}{$47+$} & 0,0363 & 0,1908 \\
\hline & & 0,0493 & 0,259 \\
\hline & & 0,0436 & 0,0641 \\
\hline
\end{tabular}

Kentte yaşayanlar içinde, 15-22 yaşında ve intihar etmeyi düşünen kadınların yüzdesi \%4,35'tir. 31-38 yaşında olanlar içinde, kentte yaşayanlar ve intihar etmeyi düşünmeyenlerin yüzdesi \% 60,4'tür. İntihar etmeyi aklından geçiren kadınların içinde, kırda yaşayan ve 39-46 yaş arasında olanların yüzdesi \% 4,32'dir.

\section{Log-Lineer Modellerin Belirlenmesi}

Tablo 5'te tanımları verilen modeller, Yaşadığı Yer*Yaş*Intihar çapraz tablosu için oluşturulmuş ve tabloya uygunlukları test edilmiştir. Test edilen ilk model $\mathrm{M}_{0}$ olup RED edilmiştir. Dolayısıyla yaşadığı yer, yaş ve intihar değișkenleri birbirinden bağımsız değildir. Diğer modeller de test edilerek tablo yapısına uygun, yani hipotez testi kabul çıkan modeller belirlenmiştir.

Tablo 5. Mo'dan M7'ye Modellerin Testi

\begin{tabular}{|c|c|c|c|c|c|}
\hline Model & Gösterim & $\mathbf{G}^{2}$ & SD & $\mathbf{P}$ & Hipotez \\
\hline $\mathbf{M}_{\mathbf{0}}$ & $(\mathrm{Y}, \mathrm{A}, \mathrm{D})$ & 130,601 & 13 & 0,000 & RED \\
\hline $\mathbf{M}_{\mathbf{1}}$ & $(\mathrm{Y}, \mathrm{A} \mathrm{D})$ & 62,477 & 9 & 0,000 & RED \\
\hline $\mathbf{M}_{\mathbf{2}}$ & $(\mathrm{A}, \mathrm{YI})$ & 129,007 & 12 & 0,000 & RED \\
\hline $\mathbf{M}_{3}$ & $(\mathrm{t}, \mathrm{YA})$ & 72,288 & 9 & 0,000 & RED \\
\hline $\mathbf{M}_{4}$ & $(\mathrm{YI}, \mathrm{AD})$ & 60,884 & 8 & 0,000 & RED \\
\hline $\mathbf{M}_{5}$ & $(\mathrm{YA}, \mathrm{AI})$ & 4,158 & 5 & 0,527 & KABUL \\
\hline $\mathbf{M}_{6}$ & $(\mathrm{YI}, \mathrm{YA})$ & 70,688 & 8 & 0,000 & RED \\
\hline $\mathbf{M}_{7}$ & $(\mathrm{YA}, \mathrm{YI}, \mathrm{AD})$ & 3,246 & 14 & 0,517 & KABUL \\
\hline
\end{tabular}

Tablo 5'ten görülebileceği gibi $\mathrm{M}_{5}$ ve $\mathrm{M}_{7}$ modelleri tablo yapısına uygundur:

$$
\begin{aligned}
& \mathrm{M}_{5}: \mathrm{I}_{\mathrm{ijk}}=\lambda+\lambda_{(\mathrm{i})} \mathrm{Y}_{+} \lambda_{(\mathrm{j})}{ }^{\mathrm{A}}+\lambda_{(\mathrm{k})}{ }^{\dot{I}}+\lambda_{(\mathrm{ij})} \mathrm{YA}_{+} \lambda_{(\mathrm{jk})}{ }^{\mathrm{AI}} \\
& \mathrm{M}_{7}: \quad \mathrm{I}_{\mathrm{ijk}}=\lambda+\lambda_{(\mathrm{i})} \mathrm{Y}_{+} \lambda_{(\mathrm{j})}{ }^{\mathrm{A}}+\lambda_{(\mathrm{k})} \dot{\mathrm{I}}_{+} \lambda_{(\mathrm{ij})}{ }^{\mathrm{A}}+ \\
& \lambda_{(\mathrm{ik})}{ }^{\mathrm{Y}}+\lambda_{(\mathrm{jk})}{ }^{\mathrm{A} \dot{\mathrm{I}}}
\end{aligned}
$$

\section{K-Yönlü Etkiler}

En uygun modelin aynı zamanda en az terim içeren model olması tercih edildiğinden, öncelikle kaçıncı dereceden etkileşimlerin önemli olduğu test edilmelidir. Test yapılırken hiyerarşik loglineer analizden yararlanılır.

Tablo 6. K-Yönlü Etkiler

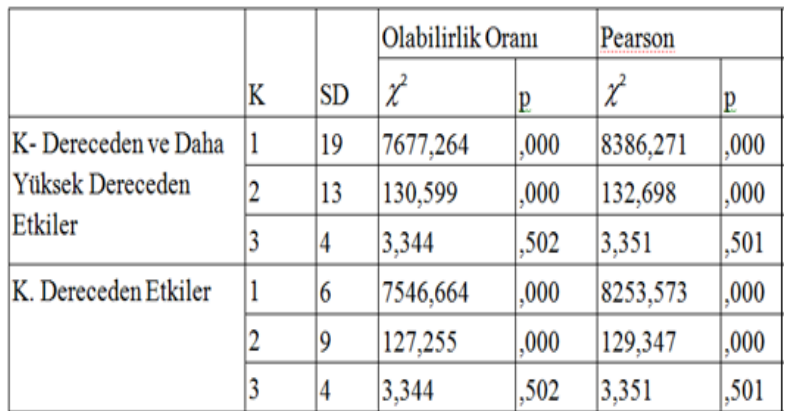


1) $\mathrm{H}_{0}: \quad \mathrm{u}_{(1)}=\mathrm{u}_{(2)}=\mathrm{u}_{(3)}=\mathrm{u}_{(12)} \quad \mathrm{u}_{(13)}=\mathrm{u}_{(23)}=0$ (Birinci dereceden/Yalın etkiler önemsizdir)

$$
\mathrm{H}_{1}: \quad \mathrm{u}_{(123)}=\mathrm{u}_{(12)}=\mathrm{u}_{(13)}=\mathrm{u}_{(123)}=0 \quad \text { (Birinci }
$$
dereceden/Yalın etkiler önemlidir)

$\mathrm{G}^{2}=7677,264$ ve $\mathrm{p}=0,000$ olduğundan dolayı $\mathrm{H}_{0} \quad$ RED edilir. Yalın etkiler önemlidir.

2) $\mathrm{H}_{0}: \mathrm{u}_{(123)}=\mathrm{u}_{(12)} \mathrm{u}_{(13)}=\mathrm{u}_{(23)}=0 \quad$ (İkinci dereceden/İkili etkiler önemsizdir)

$\mathrm{H}_{1}: \quad \mathrm{u}_{(123)}=0 \quad$ (İkinci dereceden/İkili etkiler önemlidir)

$\mathrm{G}^{2}=130,599$ ve $\mathrm{p}=0,000$ olduğundan $\mathrm{H}_{0}$ RED edilir. İkili etkiler önemlidir.

3) $H_{0}: u_{(123)}=0 \quad$ (Üçüncü dereceden/Üçlü etkiler önemsizdir)

$G^{2}=3,344$ ve $p=0,502$ olduğundan dolayı $\mathrm{H}_{0}$ KABUL edilir. Üçlü etkiler önemsizdir.

Tablo 6'dan elde edilen sonuçlara göre ana etkiler ve ikili etkileşimler önemli çıkmıştır.

\section{Kısmi ve Marjinal İlişkilerin Testi}

Tablo 6'da ikinci dereceden etkileşimlerin önemli olduğu belirlendikten sonra, hangi ikili etkileşimlerin modelde olması gerektiğine karar verebilmek amaciyla, Tablo 7'de verilen kısmi ve marjinal ilişki testleri yapılmıştır.
Tablo 7. Kısmi ve Marjinal İlişki Testi

\begin{tabular}{|l|l|l|l|l|l|}
\hline Etki & SD & $\begin{array}{l}\text { Kısmi } \\
\text { İlișki } \chi^{2}\end{array}$ & Kısmi ilișki p & Marj. İlișki $\chi^{2}$ & $\begin{array}{l}\text { Marjinal } \\
\text { İlișki p }\end{array}$ \\
\hline $\mathbf{Y}$ & 1 & 2997,703 & 0,000000 & 2997,703 & 0,000000 \\
\hline $\mathbf{A}$ & 4 & 258,157 & 0,000000 & 258,157 & 0,000000 \\
\hline$\dot{\mathrm{I}}$ & 1 & 4284,249 & 0,000000 & 4284,249 & 0,000000 \\
\hline $\mathbf{Y}^{*} \mathbf{A}$ & 4 & 57,667 & 0,000000 & 58,326 & 0,000000 \\
\hline $\mathbf{Y}^{* \dot{\mathrm{I}}}$ & 1 & 0,849 & 0,356787 & 1,508 & 0,219417 \\
\hline $\mathbf{A}^{*} \dot{\mathrm{I}}$ & 4 & 67,336 & 0,000000 & 67,993 & 0,000000 \\
\hline
\end{tabular}

Tablo 7'ye göre "Y”, “A” ve “İ” ana etkileri ile hem marjinal, hem de kısmi ilişki testinde önemli çıkan " $Y^{*} A$ " ve "A*I' ikili etkileşimlerin modelde olmasının gerektiği görülmektedir. Dolasıyla bu testlerin sonucuna göre uygun model,

$\mathrm{M}_{5}\left(\mathrm{I}_{\mathrm{ijk}}=\lambda+\lambda_{(\mathrm{i})} \mathrm{Y}+\lambda_{(\mathrm{j})}{ }^{\mathrm{A}}+\lambda_{(\mathrm{k})}{ }^{\mathrm{I}}+\lambda_{(\mathrm{ij})} \mathrm{YA}^{\mathrm{A}}+\lambda_{(\mathrm{jk})}{ }^{\mathrm{Ai}}\right)(8)$ dir.

\section{En Uygun Modelin Belirlenmesi}

En uygun modelin belirlenmesinde adımsal yöntemlere başvurulmuş; bunun için Statistica paket programı kullanılmış ve Tablo 8'de gösterildiği gibi Eşitlik (8)'deki M5 modeline ulaşılmıştır.

Tablo 8. Geriye Doğru Seçim Işslemine Göre En Iyi Model

\begin{tabular}{|l|l|l|l|}
\hline $\begin{array}{l}\text { En iyi bașlanglç modeli: } \\
\text { YA, YI, AI }\end{array}$ & $\chi^{2}=3,2478$ & SD=4 & $\mathbf{p}=0,5173$ \\
\hline En iyi model: YA, AI & $\chi^{2}=4,0974$ & SD =5 & $\mathbf{p}=0,5355$ \\
\hline
\end{tabular}

Tablo 5'te iki tane uygun model bulunduğundan, bilgi ölçütleri yardımıyla da en uygun modelin hangisinin olduğuna bak1lmas1 gerekmektedir. M5 ve M7 modelleri için elde edilen bilgi ölçütleri Tablo 9'da verilmiştir. 
Tablo 9. AIC ve BIC Sonuçları

\begin{tabular}{|l|l|l|}
\hline & AIC & BIC \\
\hline M5 & $-5,842^{*}$ & $-2,347$ \\
\hline $\mathbf{M}_{7}$ & 11,246 & $-14,968^{*}$ \\
\hline
\end{tabular}

Tablo 9'daki sonuçlara göre; AIC ölçütü ile en uygun model $\mathrm{M}_{5}$, BIC ölçütü ile en uygun model $\mathrm{M}_{7}$ olarak belirlenmiştir. Genel olarak BIC ölçütü daha güvenilir olarak değerlendirildiğinden, son olarak Tablo 10 'da verilen parametre tahminlerine bakarak en uygun modelin belirlenmesi amaçlanmıştır. Burada Z>1,96 olan etkilerin modelde yer alması gerekmektedir. Ana etkiler ile "Y*A" ve "A*ì ikili etkileşimler önemli bulunmuştur. Dolayısuyla BIC ölçütüne göre de en iyi olduğuna karar verilen $\mathrm{M}_{5}$ modeli (Eş. 8), en uygun modeldir ve intihar değişkeninin düzeylerinde, kadınların yaşadıkları yer ve yaşları birbirinden bağımsızdır.

Tablo 10. Parametre Tahminleri

\begin{tabular}{|c|c|c|c|c|c|c|c|}
\hline \multirow[b]{2}{*}{ Etki } & \multirow[b]{2}{*}{ Param. } & \multirow[b]{2}{*}{ Tahmin } & \multirow[b]{2}{*}{ Std. Hata } & \multirow[b]{2}{*}{$Z$} & \multirow[b]{2}{*}{$\mathrm{p}$} & \multicolumn{2}{|c|}{ 95\% Güven Aralığ1 } \\
\hline & & & & & & Alt sinur & Üst sınır \\
\hline \multirow{4}{*}{$\mathrm{Y}^{*} \mathrm{~A} * \mathrm{I}$} & 1 &, 007 &, 025 &, 287 &, 774 &,- 041 &, 056 \\
\hline & 2 &, 005 & ,023 &, 229 &, 819 &,- 040 &, 051 \\
\hline & 3 &,- 026 &, 024 & $-1,106$ &, 269 &,- 073 &, 020 \\
\hline & 4 &,- 022 &, 026 &,- 851 & ,395 &,- 074 &, 029 \\
\hline \multirow{4}{*}{$\mathrm{Y}^{*} \mathrm{~A}$} & 1 &,- 026 &, 025 & $-1,039$ & ,299 &,- 074 &, 023 \\
\hline & 2 & 091 &, 023 & $3,957 *$ &, 000 &, 046 &, 137 \\
\hline & 3 &, 065 &, 024 & $2,710 *$ &, 007 &, 018 &, 112 \\
\hline & 4 &,- 048 &, 026 & $-1,832 *$ &, 067 &,- 100 &, 003 \\
\hline $\mathrm{Y} * \dot{\mathrm{I}}$ & 1 &, 011 &, 012 & ,918 & ,359 &,- 013 &, 036 \\
\hline \multirow{4}{*}{$A * \dot{I}$} & 1 &, 116 &, 025 & $4,675^{*}$ &, 000 &, 067 &, 164 \\
\hline & 2 & ,081 & ,023 & $3,521 *$ &, 000 &, 036 &, 127 \\
\hline & 3 & ,000 &, 024 & ,012 & ,990 &,- 047 &, 047 \\
\hline & 4 &,- 064 &, 026 & $-2,438 *$ &, 015 &,- 116 &,- 013 \\
\hline $\mathrm{Y}$ & 1 &, 517 &, 012 & $41,705 *$ &, 000 & ,493 &, 541 \\
\hline \multirow{4}{*}{ A } & 1 &,- 084 &, 025 & $-3,388 *$ &, 001 &,- 133 &,- 035 \\
\hline & 2 &, 186 &, 023 & $8,069 *$ &, 000 &, 141 &, 232 \\
\hline & 3 &, 109 &, 024 & $4,541 *$ &, 000 &, 062 &, 155 \\
\hline & 4 &,- 157 &, 026 & $-5,955^{*}$ &, 000 &,- 208 &,- 105 \\
\hline$\dot{\mathrm{I}}$ & 1 &,- 647 &, 012 & $-52,178^{*}$ &, 000 &,- 671 &,- 622 \\
\hline
\end{tabular}

\section{Sonuç ve Öneriler}

$\mathrm{Bu}$ çalışmanın amacı, kadına yönelik şiddete dair genel yorumlar ve önerilerde bulunmak değil, üç-boyutlu tablolarda en uygun modelin nasil belirleneceğini bir uygulama üzerinde göstermektir. Ancak kadına yönelik şiddet 
konusunda üç-boyutlu çapraz tablo analizine literatürde rastlanmamıştır.

Tablo 3'ten elde edilebilecek önemli bir bulgu, 15-22 yaşındaki kadınlar söz konusu olduğunda, kentte yaşayanların hayatına son vermeyi, kırda yaşayanlara oranla fazla düşünmesidir. Toplumsal ve ahlaki kuralların kırda daha katı uygulanmasının, bu sonucun çıkmasında etkili olabileceği düşünülmektedir. Tablo 10'dan elde edilen bulgulara göre, yaş arttıkça, kadınların hayatına son verme düşüncelerinde azalma gözlenmektedir. Bunun nedeninin, kadınların sahip olduğu çocuk sayısıyla ilgili olabileceği düşünülmekle birlikte, çocuk sayısının da değişken olarak eklendiği dört-boyutlu bir çapraz tablo analizi uygulanarak araştırma yapılması daha uygun olacaktır.

Çalışma en uygun modelin seçimiyle ilişkili olduğundan, çok boyutlu tabloların log-lineer analizi yapılırken; bilgi ölçütleri ve parametre tahminlerinin en uygun modelin belirlenmesi aşamalarına dahil edilmesi ve parametre tahminleri incelenmeden en uygun modelin belirlenmemesi gerektiği sonucuna varılmıștır.

\section{Kaynaklar}

[1] Van der Heijden P G M, de Falguerolles A, de Leeuw J, 1989. A
Combined approach to contingency table analysis using correspondence analysis and log-linear analysis, Applied Statistics, 38 (2): 249-292.

[2] Y1lmaz V, Saraçlı S, 2004. Karayolları donanım durumunun trafik kaza sonuçlarına etkisi, AKÜ Fen Bilimleri Dergisi, 4 (1-2): 91-106.

[3] Mete S, Ünsal A, 2010. Kategorik veriler için logaritmik doğrusal modeller ve göç istatistikleri üzerin bir uygulama. Aksaray Üniversitesi İktisadi ve İdari Bilimler Fakültesi $\quad$ Dergisi. $8(1)$ : 299308.

[4] Öncel S Y, Erdugan F, 2015. Kontenjans tablolarının analizinde loglineer modellerin kullanımı ve sigara bağımlılı̆̆ Fen. Bil. Der. 19 (2): 221-235.

[5] Arı E, 2016. Trafik kaza verilerinin log lineer model ile incelenmesi, Süleyman Demirel Üniversitesi İktisadi ve İdari Bilimler Fakültesi Dergisi, 21 (1): 17-37.

[6] Y1lmaz V, Kesin F E, 2018. Logaritmik doğrusal modeller ve uyum analizinin birlikte kullanımı: lise öğrencilerinin sigara içme alışkanlıklarını etkileyen faktörlerin belirlenmesi, Türkiye Klinikleri J Biostat 10(1): 65-86.

[7] Bülbül S, 2006. Üç boyutlu çapraz tablolarda logaritmik doğrusal analiz: çocuk işgücü değişkenleri arasındaki etkileşimler, Uludağ Üniversitesi Iktisadi ve Idari Bilimle Fakültesi Dergisi, XXV (2): 41-70.

[8] Agresti A, 2002. Categorical Data Analysis. John Wiley \& Sons, Inc. Hoboken. New Jersey. 
[9] Becanım C, 2006. Log-lineer Modeller ve Doktor-Tıbbi Satış Mümessilleri İlişkileri Üzerine Bir Uygulama, Yüksek Lisans Tezi, Gazi Üniversitesi Fen Bilimleri Enstitüsü, Ankara.

[10] Altaş D, 2003. Lisanüstü eğitime giriş sınavı (LES) sonuçlarının üç yönlü çapraz siniflandirma tablosu ile incelenmesi, Marmara Üniversitesi İ.İ.B.F, Ekonometri Bölümü, XXI (1): 401-421

[11] Brown M B, 1976. Screening effects in multidimensional contingency tables, Applied Statistics, 25(1): 37-46.

[12] Benedetti J K, Brown, M B, 1978. Strategies for the selection of log-linear models, Biometrics, 34(4): 680-686.

[13] Christensen R, 1997. Log-Linear Models and Logistic Regression, Springer: New York. Second Edition.

[14] Powers D, Xie Y, 1999, Statistical Methods for Categorical Data Analysis, Academic Press, INC.

[15] Çağılcı T, 2019, Log Lineer Modeller ve Kadına Yönelik Şiddet Üzerine Bir Uygulama, Sinop Üniversitesi Matematik Anabilim Dalı Yüksek Lisans Tezi. 